\title{
Picture-to-picture switching in full-color thermochromic paper displays
}

\author{
Lars-Olov Hennerdal and Magnus Berggren
}

\section{Linköping University Post Print}

N.B.: When citing this work, cite the original article.

Original Publication:

Lars-Olov Hennerdal and Magnus Berggren, Picture-to-picture switching in full-color thermochromic paper displays, 2011, Applied Physics Letters, (99), 18, 183303.

http://dx.doi.org/10.1063/1.3656972

Copyright: American Institute of Physics (AIP) http://www.aip.org/

Postprint available at: Linköping University Electronic Press http://urn.kb.se/resolve?urn=urn:nbn:se:liu:diva-72821 


\title{
Picture-to-picture switching in full-color thermochromic paper displays
}

\author{
Lars-Olov Hennerdal ${ }^{1}$ and Magnus Berggren ${ }^{2, \text { a) }}$ \\ ${ }^{1}$ Acreo AB, SE-602 21 Norrköping, Sweden \\ ${ }^{2}$ Organic Electronics, ITN, Linköping University, SE-601 74 Norrköping, Sweden
}

(Received 14 June 2011; accepted 11 October 2011; published online 31 October 2011)

\begin{abstract}
Presently, we contemplate the merger of paper and electronics in different forms. There is a great desire to further explore this twinning of the information displaying features of printed papers and electronic inks. Here, we report a full-color paperboard display technology comprised of thermochromic and static inks combined with a patterned heater foil. Black and full-color thermochromic ink dots were screen-printed adjacent to, and on top of, static ink dots using a zero-angle mesh and template pattern orientation. As the heater is turned on and off, the display alter its content in between two predefined four-color pictures. (C) 2011 American Institute of Physics. [doi:10.1063/1.3656972]
\end{abstract}

Paper is the largest surface ever produced by mankind; it is a flexible and is a truly environmentally friendly substrate. Paper is today most commonly manufactured from cellulose fibers and can be converted into many different products at ultra-low costs. ${ }^{1} \mathrm{We}$ find paper as an information carrier almost everywhere in our society and there is presently a great desire to combine the features of traditional information displaying on boards and fine paper with those of low cost electronic displays to enable updating of texts and images. $^{2}$ A paper display technology holds great promise for novel functions in packaging, ${ }^{3}$ information poster displays, ${ }^{4}$ active labels,${ }^{5}$ distributed low-cost diagnostics ${ }^{6}$ and monitoring, and more. In many of the considered applications for paper displays, it is desired that the active paper surface switch in between only a few different, or even just two, text messages or images. For example, this could typically be the case for indicators displaying discrete levels of data recorded from a (printed) sensor ${ }^{7}$ and for manuals in which assembly instructions could be presented as simple animations.

Many different material systems exhibit thermochromic (TC) properties, such as conjugated polymers, ${ }^{8}$ liquid crystals (LCs), ${ }^{9}$ and dyes. ${ }^{10}$ During the last decades, in particular leuco dyes (LD) and LCs have both been extensively used in various technological applications, in scientific experiments and also as gadget functions on toys and cloths. The TC-LCs and TC-LDs are commonly processed from ink suspensions ${ }^{11}$ that includes the particular active TC material inside microcapsules. The former kind of materials is relatively more expensive but exhibit relatively better thermal accuracy as compared to the TC-LDs. The TC-LDs are often made from spiropyrans, ${ }^{10}$ fluorans, or fulgides. Various thermally activated TC displays have been explored and manufactured using traditional printing tools on plastic foils, fine paper, and other low-cost substrates. ${ }^{4,12}$

Flatbed and rotary screen-printing is widely used in order to generate information text and graphic arts onto a vast array of surfaces, such as paper, textile, and plastic foils. This technique utilizes a squeegee to force high-viscosity inks through the openings of steel or nylon woven meshes. ${ }^{13}$

\footnotetext{
${ }^{\text {a) }}$ Author to whom correspondence should be addressed. Electronic mail: magbe@itn.liu.se.
}

The screen-printing technique is suitable to pattern and deposit relatively thick ink layers as compared to what can be achieved with other techniques, such as with ink-jet, flexoprinting and so on. Also, screen-printing provides a large degree of freedom with respect to the choice of ink materials and substrate characteristics. The resolution and amount of material per dot (diameter and thickness) is in part defined by the mesh count; 77-165 mesh/cm screens are commonly used. Full-color pictures are produced by repeating the screenprinting process for each of the cyan $(\mathrm{C})$, magenta $(\mathrm{M})$, yellow (Y) and black (K) color (CMYK). To avoid raster interference (Moiré patterns) between the four different CMYK colors, the raster for each color is rotated to specific angles. Commonly used angles are for example $\mathrm{C} 15^{\circ}, \mathrm{M} 45^{\circ}, \mathrm{Y} 0^{\circ}$, and $\mathrm{K} 75^{\circ}$. Further, in screen-printing, one also must consider the risk of Moire patterns generated between the image raster and the angle of the treads of the mesh screen. This Moire patterns are kept minimal by rotating the meshes to specific angels for each of the CMYK screens and also by choosing suitable tread counts for each mesh. Typical mesh angles are C $7.5^{\circ}, \mathrm{M}$ $22.5^{\circ}$, Y $37.5^{\circ}$, and $\mathrm{K} 67.5^{\circ}$, which has to be calculated for each image screen count using for example a MMC software (MESH MOIRÉ CALCULATOR). Thus, for large-sized screen dots, i.e., low-resolution images, a zero-angle orientation between all the four screens as well as the meshes are actually possible. Screen-printing to manufacture photonics, both organic solar cells and light emitting devices, was explored since the early 1990 s by Jabbour and colleagues. ${ }^{14}$

Here, we report an all-printed TC paper display technology that can alter its image content in between two different pre-defined full-color images. Our picture-to-picture TC display includes the combination of LD-TC and traditional (static) screen-printing inks patterned on board paper combined with an aluminum resistor foil heater, see Figure 1. The heater is realized by patterning a $9 \mu \mathrm{m}$ thick aluminum layer that was pre-laminated onto a $36 \mu \mathrm{m}$ polyethylene carrier foil (provided by Skultuna Flexible AB). An aluminum serpentine heater pattern, with a total resistance of $14 \Omega$, was generated using a Graphtec FC 2200-90EX cutting plotter. The static picture, here illustrating a winter picture, is screen-printed onto the front side of the board paper (Chromolux $700,250 \mathrm{~g} / \mathrm{m}^{2}$ ) using four different $120 \mathrm{mesh} / \mathrm{cm}$ 


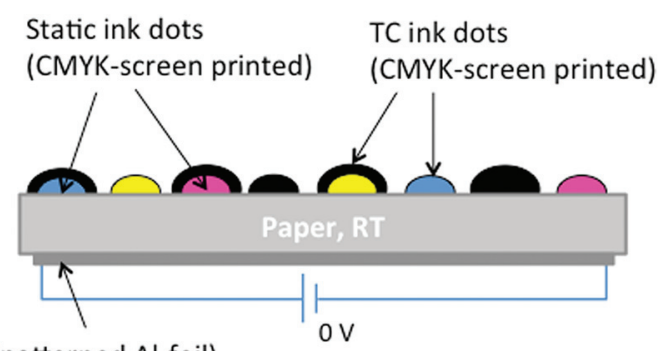

Heater (patterned Al-foil)

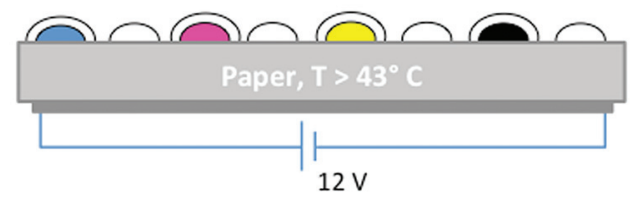

FIG. 1. (Color) The picture-to-picture TC paper display includes a first set of static screen-printed CMYK pattern dots printed on the paperboard surface. Then, a set of black TC dots are screen-printed on top of each and every one of the static CMYK patter dots. A set of CMYK TC patterns is screen-printed on the paperboard surface in the open areas in between the stacks of pattern dots. The paper display is made complete by laminating a patterned aluminum heater foil onto the backside of the paperboard. At zero bias, the "top" CMYK image is visible, here illustrated as a summer picture. As the heater is turned on $\left(\mathrm{T}>43^{\circ} \mathrm{C}\right)$, the TC ink dots turn translucent which makes the static CMYK image visible.

screens coated with a $15 \mu \mathrm{m}$ Photocap 4515 Saphir template with a zero-angle rotation with respect to each other. We use Marabu UV screen printing inks for the static image. This process generates typically $0.1-1 \mathrm{~mm}$ diameter and $10 \mu \mathrm{m}$ thick CMYK pattern dots on the paperboard. Then, a second "shutter" pattern is deposited consisting of black colored TC-LD dots (switch temperature of $43^{\circ} \mathrm{C}$, Color Change Corporation) that cover each and every of the static CMYK dots. The diameter and thickness of the TC ink dots is about $1 \mathrm{~mm}$ and approximately $10 \mu \mathrm{m}$, respectively. A zero-angle orientation was utilized also for this TC-LD pattern in order to completely cover the static CMYK dot pattern. Finally, a second image is screen-printed illustrating a summer image. This image was printed laterally in between the black TCLD/static CMYK pattern dot stacks, see Figure 1. This image was printed using TC-LD CMYK pigments (switching temperature of $43^{\circ} \mathrm{C}$, also purchased from Color Change Corporation). The pigment was mixed in Marabu Ultra Graph
UVAR 409 UV curing lacquer to a weight ratio of $20 \%$ pigment content. For this final image printing process, also here four zero-angle rotated $120 \mathrm{mesh} / \mathrm{cm}$ screens were used, which produced CMYK TC pattern dots of $0.1-1 \mathrm{~mm}$ and $10 \mu \mathrm{m}$ diameter and thickness, respectively. The two images were color separated to CMYK using a square shaped raster. Each picture was allowed to produce dots from 5\% to $50 \%$ surface coverage thereby covering at maximum $50 \%$ of the total available surface on the board and by that giving room for the second image pattern in the spaces between the first set of static ink dots. In the final step, the aluminum heater foil was laminated onto the backside of the board paper. The final structure and an illustration of the principle of operation of this picture-to-picture TC paper display are given in Figure 1.

As a $12 \mathrm{~V}$ signal is applied to the contacts of the aluminum heater, the temperature of the paper increases homogenously $\left(\mathrm{T}>43^{\circ} \mathrm{C}\right)$. The corresponding current was measured to around $0.8 \mathrm{~A}$. In Figure 2, two photographs of the pictureto-picture paper display are given, before and after the heater was turned on. The left paper display shows the "cold" image, displaying the CMYK summer picture, while the right paper display shows the "warm" image, displaying a CMYK winter picture. In the warm state, one can still discern some fractions of the cold picture. This is in particular obvious along the "blue-sky" image of the winter picture. This could be due to a slight mismatch in registration between the different templates and meshes and/or also due to a non-complete switching of the TC inks. At this particular voltage driving condition, the paper display switches from the "cold" to the "warm" image in typically just $1 \mathrm{~s}$. The return switch (off-switching) takes typically $20 \mathrm{~s}$ at a room temperature. There are several parameters that affect the switching times such as the quality of the paper, the temperature of the ambience, and switch temperature of the TC-LD inks. Typically, for TC inks with higher switch temperature, the on-switch becomes slower while the off switching becomes faster. The stability and operational lifetime of TC-LD inks are known to deteriorate upon exposure to extreme temperatures, sunlight, and aggressive solvents. Besides this, these dynamic inks are known to be robust; their shelf lifetime exceeds $1 \mathrm{yr}$ and the inks can typically be
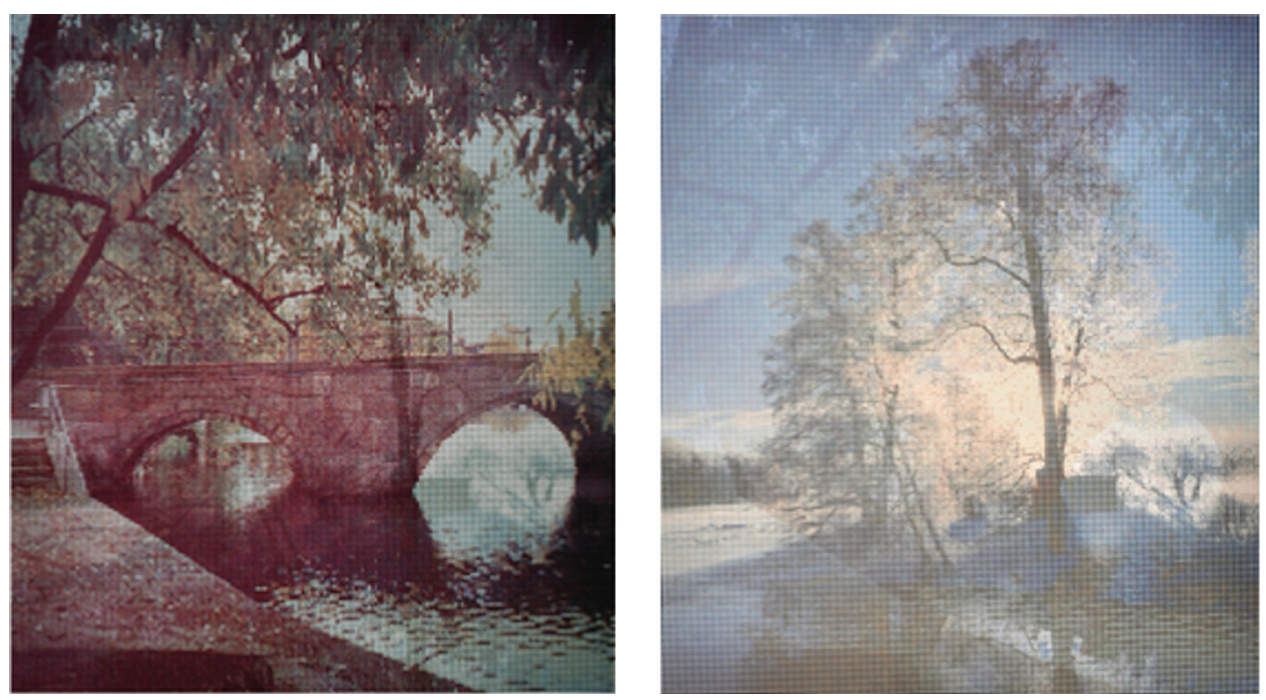

FIG. 2. (Color) Top: images of the picture-to-picture TC paper display, the unbiased state (room temperature, to the left) and in the biased state $\left(\mathrm{T}>43^{\circ} \mathrm{C}\right.$, to the right). 
switched more than $10^{4}$ times. ${ }^{15}$ While heated, and kept in its decolorized state, stability has been confirmed for TCLDs to exceed $10 \mathrm{~h}$. In our lab, TC paper displays stored for more than $1 \mathrm{yr}$, without any encapsulation, at room temperature did not exhibit any measurable degradation with respect to switch contrast or speeds. We conclude that picture-to-picture switching realized in TC-LD paper displays are preferably employed in applications for in-door use, such as in instruction display stands and signage application.

We have reported a novel approach to realize picture-topicture switching in thermochromic paper displays. Our findings demonstrate that updating of high-quality images can be realized by combining static and dynamic inks. Our results demonstrate a successful merger between graphic art technology and dynamic inks for displays. Our concept of dynamic ink dots on top of, and adjacent to, static ink dots is certainly not limited to just thermochromic color inks. Other dynamic opaque or highly absorbing display materials should be possible to utilize for similar picture-to-picture switching on different large-area and flexible substrates.

The research was performed within the frame of the PAELLA project, supported by VINNOVA, SCA, TetraPak, Stora Enso, M-Real, ITAB, and Agfa-Gevaert. The authors also wish to thank the Önnesjö foundation (Holmen), KAW, and KVA for further financial support.

${ }^{1}$ J. D. Peel, Paper Science and Paper Manufacture (Angus Wilde Publications Inc., Vancouver, BC, Canada, 1999).

${ }^{2}$ C. McAtamney, F. Pichot, A. O'Flaherty, N. Leyland, S. N. Rao, N. Stobie, M. Kinsella, D. Corr, and U. Bach, Proc. SPIE 4876, 796 (2003); R. A. Hayes and B. J. Feenstra, Nature 425, 383 (2003); A. N. Nakagaito, M.
Nogi, and H. Yano, MRS Bull. 35, 214 (2010); B. Comiskey, J. D. Albert, H. Yoshizawa, and J. Jacobson, Nature 394(6690), 253 (1998); J. Shah and R. M. Brown, Appl. Microbiol. Biotechnol. 66(4), 352 (2005); P. Andersson, D. Nilsson, P. Svensson, M. Chen, A. Malmstrom, T. Remonen, T. Kugler, and M. Berggren, Adv. Mater. 14, 1460 (2002); P. Tehrani, L. O. Hennerdal, A. L. Dyer, J. R. Reynolds, and M. Berggren, J. Mater. Chem. 19(13), 1799 (2009).

${ }^{3}$ J. M. Kuusisto, presented at the IET Seminar on Polymer Electronics: Towards the Future, Stevenage, UK, 21 April 2009.

${ }^{4}$ A. C. Siegel, S. T. Phillips, B. J. Wiley, and G. M. Whitesides, Lab Chip 9(19), 2775 (2009).

${ }^{5}$ S. Steudel, S. De Vusser, K. Myny, M. Lenes, J. Genoe, and P. Heremans, J. Appl. Phys. 99, 114519 (2006); M. Berggren, D. Nilsson, and N. D. Robinson, Nature Mater. 6(1), 3 (2007).

${ }^{6}$ F. Darain, S.-U. Park, and Y.-B. Shim, Biosens. Bioelectron. 18(5-6), 773 (2003).

${ }^{7}$ D. Gamota and Z. Jie, Printed Circ. Des. Manuf. 24, 36 (2007).

${ }^{8}$ O. Inganas and G. Gustafsson, presented at the 21 st Europhysics Conference on Macromolecular Physics: "Electrical and Optical Active Polymers" Structure, Morphology and Properties, 4-8 September 1989, Switzerland, 1990.

${ }^{9}$ C. R. Smith, D. R. Sabatino, and T. J. Praisner, Exp. Fluids 30, 190 (2001).

${ }^{10}$ A. V. Chernyshev, A. V. Metelitsa, E. B. Gaeva, N. A. Voloshin, G. S. Borodkin, and V. I. Minkin, J. Phys. Org. Chem. 20, 908 (2007).

${ }^{11}$ L. Hakola, K. Eiroma, J. Heilmann, K. Lehtinen, T. Makela, and M. Vilkman, presented at the 23rd International Conference on Digital Printing Technologies. Digital Fabrication 2007, 16-21 September 2007, Springfield, VA, USA, 2007.

${ }^{12}$ L. Liu, P. Suili, W. Weijia, and S. Ping, Appl. Phys. Lett. 90(21), 213508 (2007).

${ }^{13} \mathrm{H}$. Kipphan, Handbook of Print Media Technologies and Production Methods (Springer, New york, 2001).

${ }^{14}$ G. E. Jabbour, R. Radspinner, and N. Peyghambarian, IEEE J. Sel. Top. Quantum Electron. 7, 769 (2001); S. E. Shaheen, R. Radspinner, N. Peyghambarian, and G. E. Jabbour, Appl. Phys. Lett. 79, 2996 (2001).

${ }^{15}$ R. Kulcar, F. Mojca, N. Hauptman, A. Vesel, and M. K. Gunde, Dyes Pigm. 86(3), 271 (2010). 